\title{
Liver Transplantation in a Patient with Situs inversus Associated with Biliary Atresia, Polysplenia and Absence of Inferior Vena Cava: A Case Report
}

\author{
Henrique de Aguiar Wiederkehr ${ }^{1 *}$, Caroline Aragão de Carvalho', Matheus Ruggeri' ${ }^{1}$, \\ Lucca Cajazeira Campos' ${ }^{1}$ Barbara de Aguiar Wiederkehr'1, Julio Cesar Wiederkehr² \\ ${ }^{1}$ School of Medicine, Faculdade Evangélica do Paraná (FEPAR), Curitiba, Brazil \\ ${ }^{2}$ Department of Surgery, Federal University (UFPR), Curitiba, Brazil \\ Email: "henrique.wie@hotmail.com, carol.aragao@hotmail.com, matheus_ruggeri@hotmail.com, \\ lucca.campos@hotmail.com, barbarawie@hotmail.com, julio.wieder@gmail.com
}

Received 10 December 2015; accepted 22 February 2016; published 25 February 2016

Copyright (C) 2016 by authors and Scientific Research Publishing Inc.

This work is licensed under the Creative Commons Attribution International License (CC BY).

http://creativecommons.org/licenses/by/4.0/

(c) (i) Open Access

\begin{abstract}
Biliary atresia (BA) is the result of a process of unknown etiology which can occur as an isolated lesion or in association with several congenital abnormalities and remains the main indications of liver transplantation among infants. One of the malformations associated with biliary atresia is Situs inversus totalis, which is a rare congenital abnormality found in $10 \%-20 \%$ of infants with biliary atresia and presents an incidence varying from 1:5000 to 1:20,000. This case report aims to present an extremely rare case of a patient with Situs inversus associated with biliary atresia, polysplenia and abscence of inferior vena cava that underwent liver transplantation. Case Report: A 10-month-old boy was referred to our hospital with the diagnosis of cirrhosis, due to biliary atresia. Abdominal ultrasound and Doppler scan showed the liver in the left upper quadrant as well as signs of chronic liver disease. In addition, we could notice that the spleen had several lobes, suggesting polysplenia, and was positioned in the right upper quadrant. The patient underwent living donor liver transplant. His mother was the donor and the graft, segment III, was positioned in the left upper quadrant associated with a $\mathrm{Y}$ en Roux reconstruction of the biliary tract. During the first post-operatory day, the patient presented signs of disseminated sepsis. Laboratory and imaging diagnostic tests were performed presenting a small intestinal malrotation associated with diffuse ischemia. The patient died at the third day of PO due to complications related to this condition. Conclusion: Any patient with Situs inversus with acute abdomen should be aggressively investigated for other structural and biochemical abnormalities. If liver transplant is indicated, the procedure can be successfully performed.
\end{abstract}

${ }^{*}$ Corresponding author.

How to cite this paper: de Aguiar Wiederkehr, H., de Carvalho, C.A., Ruggeri, M., Campos, L.C., de Aguiar Wiederkehr, B. and Wiederkehr, J.C. (2016) Liver Transplantation in a Patient with Situs inversus Associated with Biliary Atresia, Polysplenia and Absence of Inferior Vena Cava: A Case Report. Surgical Science, 7, 89-95. http://dx.doi.org/10.4236/ss.2016.72012 


\section{Keywords}

\section{Liver Transplantation, Situs inversus, Polysplenia, Biliary Atresia}

\section{Introduction}

Biliary atresia (BA) is the result of a process of unknown etiology which leads to the complete obstruction or disappearance of part or all of the bile ducts in young infants. The frequency has been estimated to be $0.5-1.0$ per 10,000 live births [1]. It can occur as an isolated lesion or in association with several congenital abnormalities and remains as one of the main indications of liver transplantation among infants.

In 1959, Kasai and Suzuki reported that infants with biliary atresia could be submitted to a hepatoportoenterostomy (HPE) in order to improve their prognosis. Nevertheless, it was reported that HPE did not prevent the progession of the liver fibrosis and, consequently, cirrhosis. Therefore, an orthotopic liver transplantation is still indicated, specially in those cases of persistent cholestasis. Many reports have focused on this matter such as prognostic factors after Kasai procedure and timing for OLT [2]-[4].

One of the malformations associated with biliary atresia is Situs inversus totalis, which is a rare congenital abnormality found in $10 \%-20 \%$ of infants with biliary atresia and presents an incidence varying from 1:5000 to $1: 20,000$ [5] [6]. Situs inversus indicates mirror-image location of the viscera relative to situs solitus, which is the orthotopic position of the organs. It provides a unique challenge to the surgical team since it is often associated with BA.

There are two major subcategories of Situs inversus: Situs inversus with dextrocardia and Situs inversus with levocardia. Situs inversus with dextrocardia is more common and is characterized by mirror-image location of the heart and viscera relative to situs solitus, with the cardiac apex, spleen, stomach, and aorta located on the right and the liver and inferior vena cava (IVC) located on the left side of the body. Congenital heart disease occurs in $3 \%-5 \%$ of cases [7].

The branching pattern of the biliary tract and the location of the gallbladder in Situs inversus are mirror image relative to situs solitus. In a study by Mayo and Rice, seven of 76 patients with Situs inversus had abnormalities of the biliary tract or gallbladder. Two of the seven patients were infants with biliary atresia, and five were adults with cholelithiasis and cholecystitis [7].

This case report aims to present an extremely rare case of a patient with Situs inversus associated with biliary atresia, polysplenia and abscence of inferior vena cava that underwent liver transplantation.

\section{Case Report}

A 10-month-old boy was referred to our hospital with the diagnosis of cirrhosis, due to biliary atresia. An unsuccessfully Kasai procedure was performed at 8 weeks of age (Figure 1). At the time, he presented history of jaundice, acholic stools and dark urine since 7 days of life, persisting to this present moment.

At physical examination the child weighted $5720 \mathrm{~g}$ and was $49 \mathrm{~cm}$ tall. Chest and abdominal examination showed a right side cardiac apex and the liver positioned at the left upper quadrant. Laboratory tests revealed a total bilirrubin of $18.2 \mathrm{mg} / \mathrm{dl}$, a prothrombin time (RNI) of 1.25 and serum albumin of $2.3 \mathrm{mg} / \mathrm{dl}$. Abdominal ultrasound and Doppler scan showed the liver in the left upper quadrant as well as signs of chronic liver disease. In addition, we could notice that the spleen had several lobes, suggesting polysplenia, and was positioned in the right upper quadrant. Echocardiogram revealed a increase of the left of ventricule which confirmed the diagnosis of Situs inversus totalis with dextrocardia and normal cardiac chambers.

The patient underwent living donor liver transplant (Figure 2). His mother was the donor and a monosegment, segment III, was obtained after left lateral segmentectomy. During the recipient hepatectomy, the liver was positioned in the left upper quadrant, as shown in Figure 2, which also demonstrate the presence of polysplenia and inferior vena cava absence.

The left hepatic vein of the graft was anastomosed to the thoracic inferior vena cava (Figure 3). The left portal vein was anastomosed to the recipient portal vein (Figure 4) and hepatic artery of the recipient to the left hepatic artery of the donor graft (Figure 5). Biliary reconstruction was performed using a Roux-in-Y hepaticojejunostomy (Figure 6, Figure 7). 


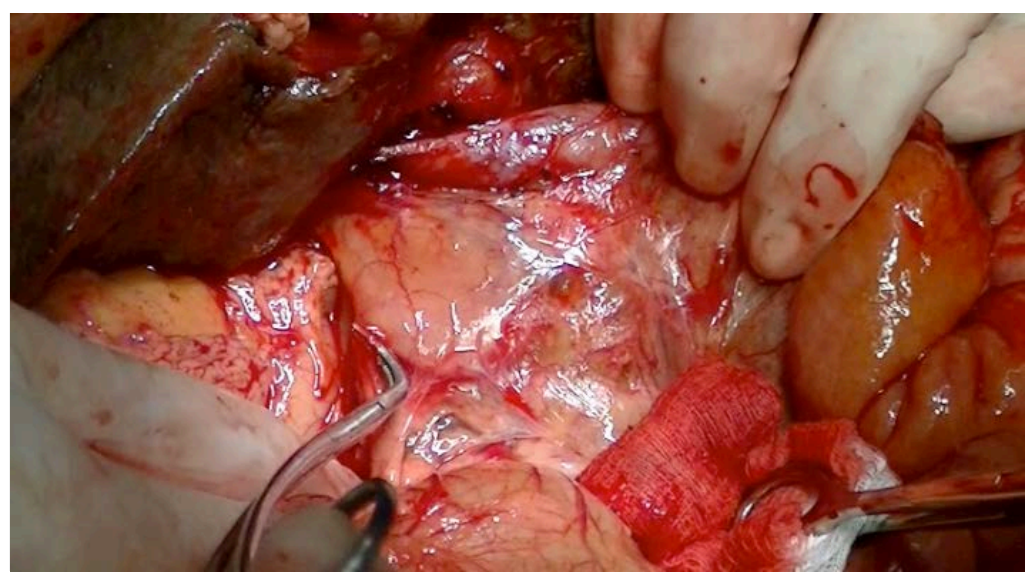

Figure 1. Image showing previous Kasai procedure.

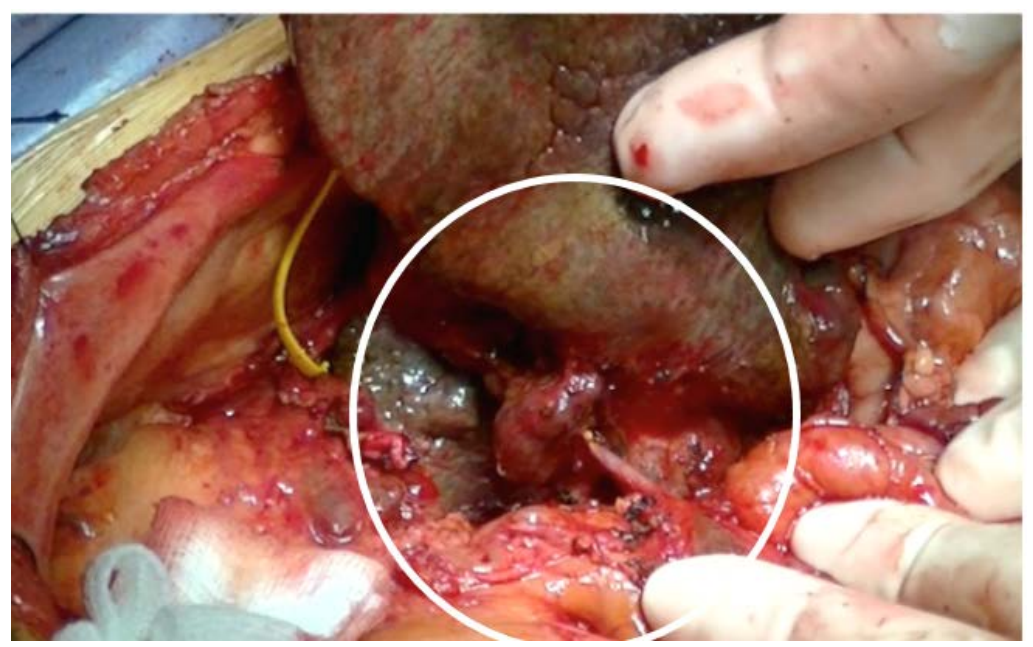

Figure 2. Absence of retro and infre hepatic inferior vena cava.

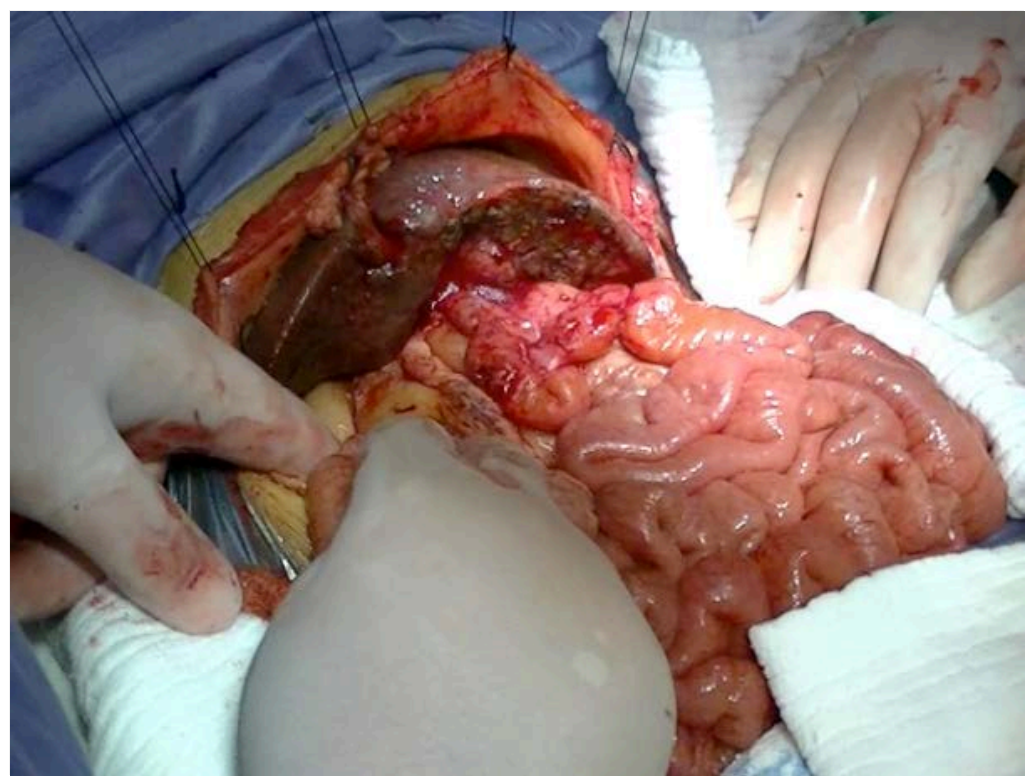

Figure 3. Liver in the left upper quadrant. 


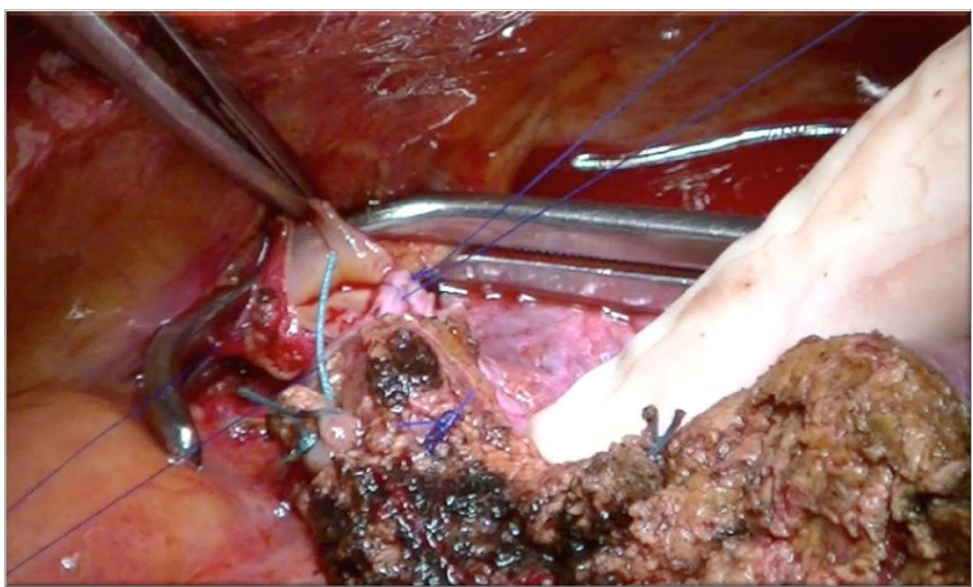

Figure 4. Left hepatic vein of the graft being anastomosed to the thoracic inferior vena cava.

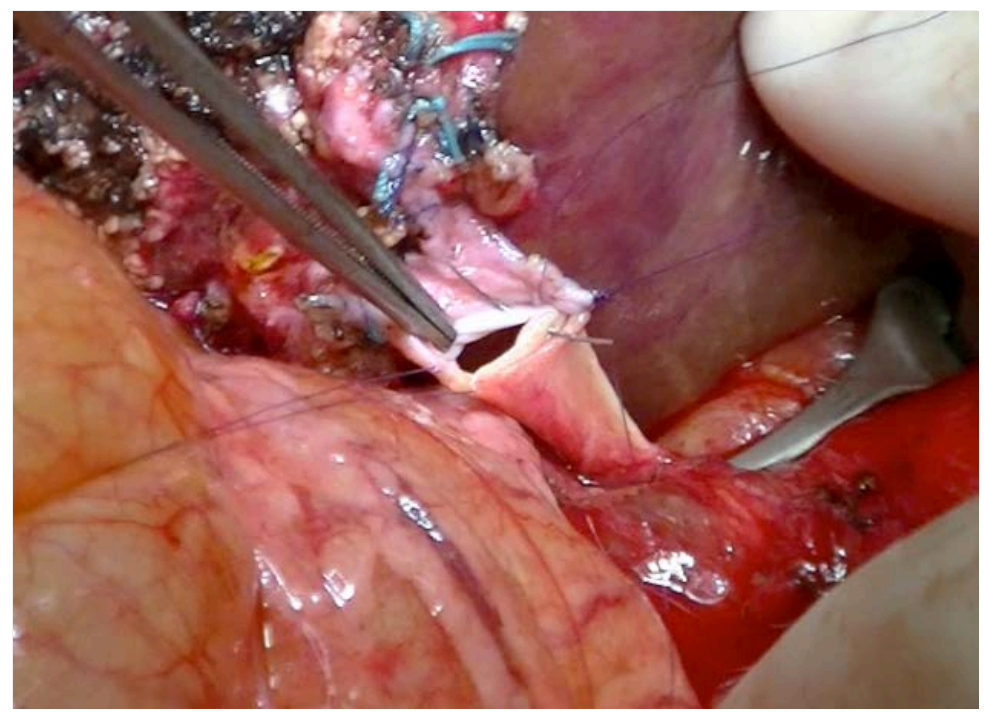

Figure 5. Left portal vein being anastomosed to the recipient portal vein.

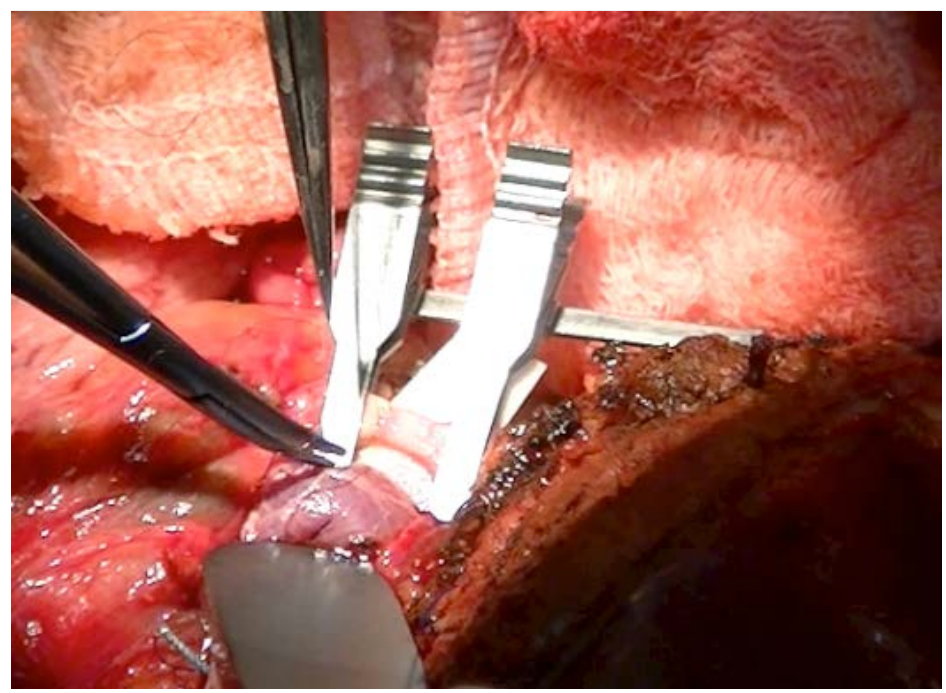

Figure 6. Hepatic artery of the recipient to the left hepatic artery of the donor graft. 


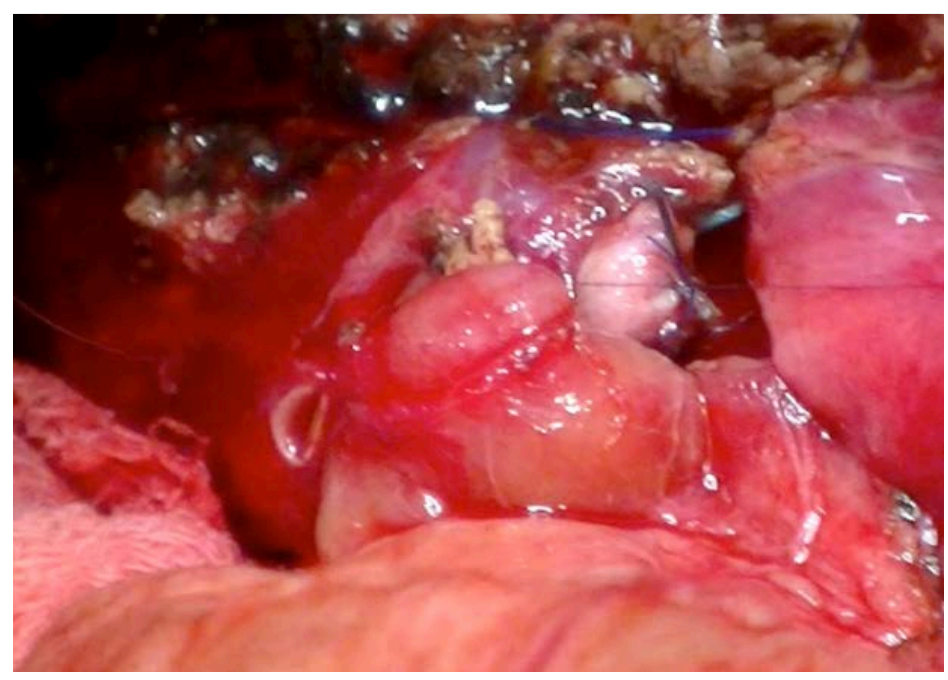

Figure 7. Hepaticjejunal anastomosis.

During the first postoperative day the patient presented signs of disseminated sepsis. During laparotomy a small intestine rotation associated with diffuse intestinal ischemia was found. Small bowel resection of the ischemic portion was performed. The patient died at the third day of PO due to complications related to bacterial translocation and sepsis caused by the small intestinal malrotation.

\section{Discussion}

The patient had Situs inversus totalis with polisplenia, dextrocardia with no cardiac chambers alterations, absence of inferior vena cava and biliary atresia. According to Tawfik et al., cardiac anomalies are generally less common in polysplenia syndrome when compared with others malformations [7] [8]. Also, the association of Situs inversus totalis and polysplenia has been briefly described in literature, however, it is unclear which malformations come first or even whether if they are actually associated with since they can be found independently. Polysplenia must be differentiate from polysplenia syndrome, known as one heterotaxy syndrome, which has not only the presence of multiple aberrant splenic nodules but also the presence of abnormal organs arrangement and isomerism of the left atrium.

Situs inversus totalis (SIT) is a very uncommon entity with a wide range of other conditions associated with. It was first reported by Fabricius in 1600 [9].

The incidence of Situs inversus totalis in patients with polysplenia described in the study by Tawfik et al. was more than 20\% [8]. In another study, Situs inversus was present in four out of ten infants with polysplenia, three of whom had biliary atresia [10]. Representing an important factor to be considered in infants with abnormal organs arrangements.

The biliary atresia remains the main indication for orthotopic liver transplantation in small children but also the surgical team must consider the possibility other malformations are commonly associated with polysplenia such as abscense of inferior vena cava, which generally continues on azygous, and makes the liver transplant in these situations more difficult and a challenge for the surgical team [8].

According to Broniszczak et al., 2011, during 2000 to 2010 were performed 401 liver transplants among which 358 were in children including 6 patients with biliary atresia and polysplenia. Of these we found a wide range of malformations such as: absence of retrohepatic vena cava [3], intestinal malrotation [3], portal vein preduodenal [1], hepatic artery abnormalities [3], cardiac abnormalities [2] and Situs inversus [10].

Once biliary atresia coexists with congenital malformations in $10 \%-25 \%$ of patients we are once again forced to look after a more complex diagnosis [11]-[13]. In the case presented in this report, we speculate that might have been a teratogenic insult about the fifth week of gestation, when the spleen and extrahepatic biliary ducts begin to develop may lead to biliary atresia and polysplenia syndrome. While for Chandra et al. Situs inversus is decided by the third week, related probably as several genes mutations, such as CFC1, SHROOM3, and others. 
One other important complication frequently associated with this condition is the abnormal intestinal malrotation, which could be found in $40 \%$ to $90 \%$ in this patient population [14] [15]. Members of the surgical team must be aware of this complication although the treatment algorithm for evaluating and treating suspected malrotation in asymptomatic patients with Situs inversus remains inconsistent [16].

Other cases similar to this one were reported in the Liver Transplantation Journal. One of those were a retrospective review of all pediatric patients undergoing LDLT from October 1995 to October 2012 in order to select patients with Situs inversus and other conditions associated with this entity. Nine patients were found and like our case, presented biliary atresia as the indication for liver transplantation. The recipients presented ages ranging from 6 to 22 months of old and five of them had previously undergone the Kasai operation. As for the vascular anatomy, the retrohepatic vena cava was also absent for 7 of the 9 patients, representing an important malformation associated with Situs inversus. Other similarity of this article with our case was the small bowel perforation complication also found in one patient from the series [17].

Follow-up and prognosis of patients with SI who underwent liver transplantation depends on which malformation was associated to this condition. Nevertheless, according to early reports [17]-[19] the liver transplant can be successfully performed in this kind of patient. A follow-up of the vascular anastomosis must be performed with a doppler ultrasound every six months in the first two years to evaluate the patency and the success of the procedure.

\section{Conclusions}

Any patient with Situs inversus with acute abdomen should be aggressively investigated for other structural and biochemical abnormalities that could potentially be associated such as biliary atresia, polysplenia and absence of inferior vena cava.

If liver transplant is indicated, the procedure can be successfully performed. Although, the vascular anomalies and graft positioning could represent a technical challenge for the surgical team.

\section{Conflict of Interest Statement}

No conflict of interest exists.

\section{Role of Funding Sources}

No funding sources exist.

\section{References}

[1] Silveira, T.R., Salzano, F.M., Howard, E.R. and Mowart, A.P. (1992) Congenital Structural Abnormalities in Biliary Atresia: Evidence for Etiopathogenic Heterogeneity and Therapeutic Implications. Acta Paediatrica Scandinavica, 80, 1192-1199. http://dx.doi.org/10.1111/j.1651-2227.1991.tb11808.x

[2] Mirza, B., Iqbal, S. and Sheikh, A. (2012) Biliary Atresia Associated with Polysplenia Syndrome, Situs inversus Abdominus, and Reverse Rotation of Intestine. APSP Journal of Case Reports, 3, 14.

[3] Toyoki, Y., Hakamada, K., Narumi, S., Nara, M., Sugai, M., Munakata, H., et al. (2008) Timing for Orthotopic Liver Transplantation in Children with Biliary Atresia: A Single-Center Experience. Transplantation Proceedings, 40, 24942496. http://dx.doi.org/10.1016/j.transproceed.2008.08.043

[4] Hahn, S.M., Kim, S., Park, K.I., Han, S.J. and Koh, H. (2013) Clinical Benefit of Liver Stiffness Measurement at 3 Months after Kasai Hepatoportoenterostomy to Predict the Liver Related Events in Biliary Atresia. PLoS ONE, 8, e80652. http://dx.doi.org/10.1371/journal.pone.0080652

[5] Rayhill, S.C., Scott, D., Orloff, S., Horn, J.-L., Schwartz, J., Zaman, A., et al. (2009) Orthotopic, but Reversed Implantation of the Liver Allograft in Situs inversus Totalis-A Simple New Approach to a Difficult Problem. American Journal of Transplantation, 9, 1602-1606. http://dx.doi.org/10.1111/j.1600-6143.2009.02676.x

[6] Borgaonkar, V.D., Deshpande, S.S. and Kulkarni, V.V. (2011) Laparoscopic Cholecystectomy and Appendicectomy in Situs inversus Totalis: A Case Report and Review of Literature. Journal of Minimal Access Surgery, 7, 242-245. http://dx.doi.org/10.4103/0972-9941.85649

[7] Fulcher, A.S. and Turner, M.A. (2013) Abdominal Manifestations of Situs Anomalies in Adults. Radiological Society of North America. 
[8] Tawfik, A.M., Batouty, N.M., Zaky, M.M., Eladalany, M.A. and Elmokadem, A.H. (2013) Polysplenia Syndrome: A Review of the Relationship with Viscero-Atrial Situs and the Spectrum of Extra-Cardiac Anomalies. Surgical and Radiologic Anatomy, 35, 647-653. http://dx.doi.org/10.1007/s00276-013-1100-x

[9] Yaghan, R.J., Gharaibeh, K.I. and Hammori, S. (2001) Feasibility of Laparoscopic Cholecystectomy in Situs inversus. Journal of Laparoendoscopic and Advanced Surgical Techniques: Part A, 11, 233-237. http://dx.doi.org/10.1089/109264201750539763

[10] Chandra, R.S. (1974) Biliary Atresia and Other Structural Anomalies in the Congenital Polysplenia Syndrome. Journal of Pediatrics, 85, 649-655. http://dx.doi.org/10.1016/S0022-3476(74)80508-1

[11] Broniszczak, D., Apanasiewicz, A., Czubkowski, P., Kaliciński, P., Ismail, H., Ostoja-Chyzynska, A., et al. (2011) Liver Transplantation in Children with Biliary Atresia and Polysplenia Syndrome. Annals of Transplantation, 16, 1417.

[12] Karrer, F.M., Hall, R.J. and Lilly, J.R. (1991) Biliary Atresia and the Polysplenia Syndrome. Journal of Pediatric Surgery, 26, 524-527. http://dx.doi.org/10.1016/0022-3468(91)90697-R

[13] Tanano, H., Hasegawa, T., Kawahara, H., Sasaki, T. and Okada, A. (1999) Biliary Atresia Associated with Congenital Structural Anomalies. Journal of Pediatric Surgery, 34, 1687-1690. http://dx.doi.org/10.1016/S0022-3468(99)90645-0

[14] Ditchfield, M.R. and Hutson, J.M. (1998) Intestinal Rotational Abnormalities in Polysplenia and Asplenia Syndromes. Pediatric Radiology, 28, 303-306. http://dx.doi.org/10.1007/s002470050358

[15] Nakada, K., Kawaguchi, F., Wakisaka, M., et al. (1997) Digestive Tract Disorders Associated with Asplenia/Polysplenia Syndrome. Journal of Pediatric Surgery, 32, 91-94. http://dx.doi.org/10.1016/S0022-3468(97)90103-2

[16] Hill, S.J., Heiss, K.F., Mittal, R., Clabby, M.L., Durham, M.M., Ricketts, R. and Wulkan, M.L. (2014) Heterotaxy Syndrome and Malrotation: Does Isomerism Influence Risk and Decision to Treat. Journal of Pediatric Surgery, 49, 934-937. http://dx.doi.org/10.1016/j.jpedsurg.2014.01.026

[17] Vincenzi, R., Seda-Neto, J., da Fonseca, E.A., Ketzer, B.M., Benavides, M., Cândido, H.L., Porta, G., Miura, I.K., Pugliese, R., Danesi, V.B., Guimaraes, T.C., Porta, A., Borges, C.B., Kondo, M. and Chapchap, P. (2013) Technical Aspects and Outcomes of Living Donor Liver Transplantation for Pediatric Patients with Situs inversus. Liver Transplantation, 19, 431-436. http://dx.doi.org/10.1002/lt.23611

[18] Farmer, D.G., Shaked, A., Olthoff, K.M., Imagawa, D.K., Millis, J.M. and Busuttil, R.W. (1995) Evaluation, Operative Management, and Outcome after Liver Transplantation in Children with Biliary Atresia and Situs Inversus. Annals of Surgery, 222. http://dx.doi.org/10.1097/00000658-199507000-00008

[19] Matsubara, K., Fujimoto, Y., Kamei, H., Ogawa, K., Kasahara, M., Ueda, M., et al. (2005) Living Donor Liver Transplantation for Biliary Atresia Complicated by Situs inversus: Technical Highlights. Liver Transplantation, 11, $1444-$ 1447. http://dx.doi.org/10.1002/lt.20584 